\title{
Effects of forms and rates of potassium fertilizers on cadmium uptake by two cultivars of spring wheat (Triticum aestivum, L.)
}

\author{
Zhong-Qiu Zhao ${ }^{\mathrm{a}}$, Yong-Guan Zhu ${ }^{\mathrm{a}, *}$, Hui-Ying Li ${ }^{\mathrm{b}, \mathrm{c}}$, Sally E. Smith ${ }^{\mathrm{c}}$, F. Andrew Smith ${ }^{\mathrm{c}}$ \\ ${ }^{a}$ Research Center for Eco-environmental Sciences, Chinese Academy of Sciences, Beijing 100085, China \\ ${ }^{\mathrm{b}}$ Institute of Genetics and Developmental Biology, Chinese Academy of Sciences, Shijiazhuang, China \\ ${ }^{\mathrm{c}}$ Department of Soil and Water, The University of Adelaide, Glen Osmond SA5064, Australia
}

Received 9 December 2002; accepted 6 March 2003

\begin{abstract}
A greenhouse pot experiment was conducted to study the influence of potassium fertilizers in different forms and rates on cadmium (Cd) uptake by two cultivars of spring wheat (Triticum aestivum, L.): Brookton and Krichauff. Potassium fertilizers were added to soil at four levels: $0,55,110$ and $166 \mathrm{mg} \mathrm{K} \mathrm{kg}{ }^{-1}$ soil as $\mathrm{KNO}_{3}(\mathrm{~N}), \mathrm{KCl}(\mathrm{C})$ or $\mathrm{K}_{2} \mathrm{SO}_{4}(\mathrm{~S}) \cdot \mathrm{CdCl}_{2}$ was added to all the treatments at a uniform rate equivalent to $15 \mathrm{mg} \mathrm{Cd} \mathrm{kg}^{-1}$ soil. Plant shoot and root dry weights (DW) of both cultivars were reduced significantly by the addition of Kfertilizer in $\mathrm{C}$ and $\mathrm{S}$ treatments but there were only marginal changes in the $\mathrm{N}$ treatments. The Cd concentrations in shoots and whole plants increased significantly $(P<.001)$ with increasing $\mathrm{K}$ addition, from 37.5 to $81.4 \mathrm{mg} \mathrm{kg}^{-1}$ and from 42.9 to $86.8 \mathrm{mg} \mathrm{kg}^{-1}$ for Brookton and Krichauff, respectively. However, no obvious effect was observed in the $\mathrm{N}$ treatments, except for the highest K level (K3) where there was a sharp increase in $\mathrm{Cd}$ concentration compared to the lower additions. Forms of K-fertilizers significantly influenced the Cd concentrations in plant shoots and roots $(P<.001)$, but there was no significant difference between $\mathrm{C}$ and $\mathrm{S}$ treatments. This experiment showed that anions $\mathrm{Cl}^{-}$and $\mathrm{SO}_{4}^{2-}$ increase $\mathrm{Cd}$ uptake by plants, which can be interpreted as $\mathrm{Cl}^{-}$and $\mathrm{SO}_{4}^{2-}$ complexing readily with $\mathrm{Cd}^{2+}$ and thereby increasing the bioavailability of $\mathrm{Cd}^{2+}$ in soils. The effect of potassium itself on plant uptake of Cd was also observed. We suggest that when applying potassium fertilizer to Cd-contaminated soils, the forms and rates should be considered.
\end{abstract}

(C) 2003 Elsevier Science Ltd. All rights reserved.

Keywords: Anion; Potassium fertilizers; Cadmium uptake; Spring wheat

\section{Introduction}

Cadmium $(\mathrm{Cd})$, one of the nonessential and toxic heavy metals, can be transferred via the food chains and accumulate in human bodies. Cadmium in the body can result in many health problems such as itai-itai disease, renal dysfunction, liver damage, lung edema, anemia and hypertension (Basta et al., 1998). With the addition of Cdcontaining manures, fertilizers, sewage, biosolids and other soil amendments and atmospheric deposition, soil contamination is becoming serious over large areas. Several studies reported that environmental contamination with cadmium caused serious human health problems in some parts of China (Cai et al., 1990; Nordberg et al., 1997). Accordingly,

\footnotetext{
* Corresponding author. Tel.: +86-10-6293-6940; fax: +86-10-62923563.

E-mail address: ygzhu@mail.rcees.ac.cn (Y.-G. Zhu).
}

soil contamination with $\mathrm{Cd}$ and other heavy metals and plant uptake of those heavy metals has been one of the focuses of environmental science because of their transportation and accumulation in food chains.

Many factors affect cadmium transport and accumulation in plant-soil systems, such as soil $\mathrm{pH}$, soil redox potential, cation exchange capacity, plant species and fertilizer application, etc. (Chaney and Hornick, 1978). Nitrogen (N) and phosphorus (P) fertilizer application may increase $\mathrm{Cd}$ accumulation in plants (Oliver et al., 1993; Grant and Baily, 1997; Basta et al., 1998), and the effect of different $\mathrm{N}$ sources and rates vary markedly (Eriksson, 1990; Willaert and Verloo, 1992; Mair et al., 2002). Much work has been done by Zhu (2001) and Zhu et al. (1999, 2000, 2002) on the interaction between potassium $(\mathrm{K})$ and ${ }^{137} \mathrm{Cs}$, which has shown that $\mathrm{K}$ significantly affected ${ }^{137} \mathrm{Cs}$ uptake by plants. Few studies have yet been done on the relationship between potassium fertilizer and Cd uptake by plants. Sparrow et al. (1994) showed that addition of $\mathrm{K}$ as $\mathrm{KCl}$ increased $\mathrm{Cd}$ 
concentrations in potato tubers compared to the equivalent amount of $\mathrm{K}$ as $\mathrm{K}_{2} \mathrm{SO}_{4}$. Grant et al. (1996) suggested that $\mathrm{KCl}$ increased $\mathrm{Cd}$ concentration in barley grain. In contrast, a field experiment conducted by McLaughlin et al. (1995) showed no influence of various $\mathrm{K}$ forms $\left(\mathrm{KCl}, \mathrm{K}_{2} \mathrm{SO}_{4}\right)$ on $\mathrm{Cd}$ concentrations in potato tubers.

$\mathrm{K}$ fertilizers are always accompanied by anions such as chloride and sulfate, which have been reported to increase $\mathrm{Cd}$ concentrations in plants. Some investigations have been carried out on effects of chloride and sulfate on Cd uptake by plants. Bingham et al. $(1984,1986)$ first reported that chloride and sulfate increased Cd uptake by Swiss chard (Beta vulgaris L.). Li et al. (1994) and McLaughlin et al. (1994) found in field experiments that soil salinity (chloride) was an important factor influencing $\mathrm{Cd}$ concentrations in field crops. Recently, a field survey conducted by Norvell et al. (2000) showed that the accumulation of $\mathrm{Cd}$ in durum wheat grain was strongly and positively associated with soil salinity. Smolders and McLaughlin (1996) and Smolders et al. (1996) demonstrated that $\mathrm{Cd}^{2+}$ complexes with $\mathrm{Cl}$ to form $\mathrm{CdCl}_{n}^{2-n}$, which appeared to be available to plants. Both solution culture and pot experiments using soil, however, suggested that addition of sulfate did not affect, or only marginally increased $\mathrm{Cd}$ uptake by plants, although addition of sulfate decreased free $\mathrm{Cd}^{2+}$ concentration in soil solution markedly or increased $\mathrm{Cd}$ concentrations in soil solution.

As an important macronutrient, and one of the dominating factors of soil cation exchange capacity (CEC), K may possibly influence $\mathrm{Cd}$ transportation and accumulation in soil-plant systems. In the present experiment, we investigated the effects of $\mathrm{K}$ fertilizers in different forms and at different rates on the biomass and $\mathrm{Cd}$ concentration in two different cultivars of spring wheat.

\section{Materials and methods}

\subsection{Soils}

This study involved a pot experiment (Table 1). A loamy soil $(0-25 \mathrm{~cm})$ was taken from the Luancheng Experimental Station, Chinese Academy of Sciences (CAS), Shijiazhuang. The soil samples were air dried and sieved $(<2$ $\mathrm{mm}$ stainless steel mesh) before analysis of chemical properties. Soil chemical properties were measured using methods recommended by the Chinese Society of Soil Science (Lu, 1999). Soil $\mathrm{pH}$ was measured in a 1:1 soil/water suspension with a combination electrode. Available $\mathrm{N}$ was extracted using $2 \mathrm{M} \mathrm{KCl}$ solution, available $\mathrm{P}$ was extracted using $0.5 \mathrm{M} \mathrm{NaHCO}_{3}$ and available $\mathrm{K}$ was extracted using neutral $1 \mathrm{M} \mathrm{NH}_{4} \mathrm{OAC}$. Cation exchange capacity (CEC) was measured using the method of displacing exchangeable cations on soil particles with $\mathrm{NH}_{4}^{+}$followed by $\mathrm{NH}_{4}^{+}$ determination. The soil was supplied with three forms of $\mathrm{K}$ fertilizers: $\mathrm{KNO}_{3}(\mathrm{~N}), \mathrm{KCl}(\mathrm{C})$ and $\mathrm{K}_{2} \mathrm{SO}_{4}(\mathrm{~S})$, and at four levels: CK $(0 \mathrm{~K}), \mathrm{K} 1\left(55 \mathrm{mg} \mathrm{K} \mathrm{kg}^{-1}\right.$ soil), K2 (110 mg K $\mathrm{kg}^{-1}$ soil) and $\mathrm{K} 3$ (166 $\mathrm{mg} \mathrm{K} \mathrm{kg}^{-1}$ soil). Thus, altogether, there were 12 treatments. $\mathrm{CdCl}_{2}$ was added to all the treatments at a uniform level equivalent to $15 \mathrm{mg} \mathrm{Cd}$ $\mathrm{kg}^{-1}$ soil, and there was uniform application of $\mathrm{N}-\mathrm{P}$ fertilizer at amounts equal to $200 \mathrm{mg} \mathrm{N} \mathrm{kg}^{-1}$ soil (added as urea) and $133 \mathrm{mg} \mathrm{P}_{2} \mathrm{O}_{5} \mathrm{~kg}^{-1}$ soil (added as $\mathrm{CaHPO}_{4}$ ). Each treatment had four replicates.

\subsection{Plant culture}

The treated soils were mixed thoroughly and taken into plastic pots $(1 \mathrm{~kg} / \mathrm{pot})$ and saturated with deionized water. Soil was allowed to equilibrate in the greenhouse for 1 week before sowing the seeds. Four germinated seeds of two cultivars of spring wheat (Triticum aestivum, L.), Brookton and Krichauff (from The University of Adelaide, Australia), were planted in each pot. The pots were randomly arranged in a greenhouse and rearranged several times during the growth period. When the seedlings had grown to about $3 \mathrm{~cm}$, they were thinned to three per pot. The seedlings were irrigated with deionized water every 3 days, maintaining the soil moisture content at $15 \%(\mathrm{w} / \mathrm{w})$ by weighing. The growth temperature was $25{ }^{\circ} \mathrm{C}$ on average during 14/10 h light/dark cycles. After 7 weeks, the plants were harvested.

\subsection{Plant analysis}

After harvest, the seedlings were separated into shoots and roots and rinsed thoroughly with deionized water, and the fresh weights were determined. The samples were then oven dried at $70{ }^{\circ} \mathrm{C}$ for $48 \mathrm{~h}$, and the dry weight (DW) of shoots and roots were recorded. Dried plant samples were finely ground in a stainless steel miller.

Subsamples $(0.25 \mathrm{~g})$ of finely ground plant materials were digested at $160{ }^{\circ} \mathrm{C}$ in $5 \mathrm{ml}$ high-purity mixed acid $\left(\mathrm{HNO}_{3} / \mathrm{HClO}_{4}=6: 1\right)$. Reference material (GBW07605) was used for quality control of acid digestion and instrument performance. The digest was diluted to $50 \mathrm{ml}$ using highpurity water, and the concentration of $\mathrm{Cd}$ in the digest was determined by inductively coupled plasma mass spectrometry (ICP-MS, Agilent 7500a, USA).

Table 1

Selected chemical properties of the soil used in the pot experiment

\begin{tabular}{lllllll}
\hline $\mathrm{pH}$ & $\mathrm{OM}$ & Available $\mathrm{N}$ & Available P \\
$(\%)$ & $\left(\mathrm{mg} \mathrm{kg}^{-1}\right)$ & $\begin{array}{l}\text { Available K } \\
\left(\mathrm{mg} \mathrm{kg}^{-1}\right)\end{array}$ & $\begin{array}{l}\text { CEC } \\
\left(\mathrm{cmol} / \mathrm{kg}^{-1}\right)\end{array}$ & $\begin{array}{l}\text { Total Cd } \\
\left(\mathrm{mg} \mathrm{kg}^{-1}\right)\end{array}$ \\
\hline 7.7 & 1.4 & 80.0 & 24.1 & 198.7 & 10.0 & 176.6 \\
\hline
\end{tabular}


Table 2

Shoot biomass of spring wheat plants grown in pot culture with different forms and levels of K-fertilizers $(\mathrm{g})$

\begin{tabular}{|c|c|c|c|c|c|}
\hline \multirow[t]{2}{*}{ Cultivar } & \multirow[t]{2}{*}{ Form } & \multicolumn{4}{|c|}{ Levels of potassium addition $\left(\mathrm{mg} \mathrm{kg}^{-1}\right)$} \\
\hline & & 0 & 55 & 110 & 166 \\
\hline \multirow[t]{3}{*}{ Brookton } & $\mathrm{KCl}$ & & $2.4 \pm 0.2$ & $2.4 \pm 0.1$ & $2.2 \pm 0.1$ \\
\hline & $\mathrm{KNO}_{3}$ & $2.6 \pm 0.0$ & $3.0 \pm 0.5$ & $2.9 \pm 0.1$ & $2.5 \pm 0.1$ \\
\hline & $\mathrm{K}_{2} \mathrm{SO}_{4}$ & & $2.1 \pm 0.0$ & $2.3 \pm 0.1$ & $2.2 \pm 0.1$ \\
\hline \multirow[t]{3}{*}{ Krichauff } & $\mathrm{KCl}$ & & $2.4 \pm 0.1$ & $2.2 \pm 0.2$ & $2.0 \pm 0.1$ \\
\hline & $\mathrm{KNO}_{3}$ & $2.8 \pm 0.2$ & $2.1 \pm 0.1$ & $2.5 \pm 0.1$ & $2.5 \pm 0.2$ \\
\hline & $\mathrm{K}_{2} \mathrm{SO}_{4}$ & & $2.1 \pm 0.1$ & $2.4 \pm 0.1$ & $2.1 \pm 0.0$ \\
\hline
\end{tabular}

Analysis of variance

\begin{tabular}{ll}
\hline K-form $(F)$ & $P<.001$ \\
K-level $(L)$ & $P<.001$ \\
Cultivar $(C)$ & $\mathrm{NS}$ \\
$F * L$ & $P=.048$ \\
$F * C$ & $\mathrm{NS}$ \\
$L * C$ & $P=.018$ \\
$F * L * C$ & $\mathrm{NS}$ \\
\hline
\end{tabular}

\subsection{Statistical analysis}

All data were subjected to the analysis of variance (ANOVA) using commercially available GENSTAT $\left(6^{\text {th }}\right.$ ed., NAG, England).

\section{Results}

\subsection{Plant dry weights}

Increasing the application of $\mathrm{K}$ fertilizer as $\mathrm{KCl}$ and $\mathrm{K}_{2} \mathrm{SO}_{4}$ significantly reduced the dry weights of plant shoots and roots in both cultivars, but no obvious change was observed in the treatments of $\mathrm{KNO}_{3}$ (Tables 2 and 3). The dry weights in the treatments $\mathrm{KNO}_{3}$ were generally higher than those in the other treatments. There was no significant

Table 3

Root biomass of spring wheat plants grown in pot culture with different forms and levels of K-fertilizers (g)

\begin{tabular}{llllll}
\hline Cultivar & Form & \multicolumn{4}{l}{ Levels of potassium addition $\left(\mathrm{mg} \mathrm{kg}^{-1}\right)$} \\
\cline { 3 - 6 } & & 0 & 55 & 110 & 166 \\
\hline Brookton & $\mathrm{KCl}$ & & $0.36 \pm 0.04$ & $0.36 \pm 0.01$ & $0.32 \pm 0.03$ \\
& $\mathrm{KNO}_{3}$ & $0.36 \pm 0.02$ & $0.40 \pm 0.06$ & $0.48 \pm 0.02$ & $0.37 \pm 0.01$ \\
& $\mathrm{~K}_{2} \mathrm{SO}_{4}$ & & $0.30 \pm 0.01$ & $0.33 \pm 0.03$ & $0.33 \pm 0.01$ \\
Krichauff & $\mathrm{KCl}$ & $0.36 \pm 0.01$ & $0.33 \pm 0.01$ & $0.34 \pm 0.02$ \\
& $\mathrm{KNO}_{3}$ & $0.42 \pm 0.06$ & $0.29 \pm 0.02$ & $0.34 \pm 0.01$ & $0.36 \pm 0.01$ \\
& $\mathrm{~K}_{2} \mathrm{SO}_{4}$ & & $0.27 \pm 0.02$ & $0.32 \pm 0.00$ & $0.32 \pm 0.01$
\end{tabular}

Analysis of variance

\begin{tabular}{ll}
\hline K-form $(F)$ & $P=.008$ \\
K-level $(L)$ & $P=.002$ \\
Cultivar $(C)$ & NS \\
$F * L$ & NS \\
$F * C$ & NS \\
$L * C$ & $P=.003$ \\
$F * L * C$ & NS
\end{tabular}

K-level $(L) \quad P=.002$

Cultivar $(C)$ NS

$F * L \quad$ NS

$F * L * C \quad$ NS
Table 4

$\mathrm{K}$ concentrations in shoots of spring wheat plants grown in pot culture with different forms and levels of K-fertilizers $\left(\mathrm{g} \mathrm{kg}^{-1}\right)$

\begin{tabular}{|c|c|c|c|c|c|}
\hline \multirow[t]{2}{*}{ Cultivar } & \multirow[t]{2}{*}{ Form } & \multicolumn{4}{|c|}{ Levels of potassium addition $\left(\mathrm{mg} \mathrm{kg}^{-1}\right)$} \\
\hline & & 0 & 55 & 110 & 166 \\
\hline \multirow[t]{3}{*}{ Brookton } & $\mathrm{KCl}$ & & $37.4 \pm 1.3$ & $37.9 \pm 0.5$ & $39.0 \pm 0.7$ \\
\hline & $\mathrm{KNO}_{3}$ & $30.9 \pm 0.20$ & $32.7 \pm 0.6$ & $34.4 \pm 0.7$ & $36.7 \pm 0.5$ \\
\hline & $\mathrm{K}_{2} \mathrm{SO}_{4}$ & & $36.8 \pm 0.6$ & $39.4 \pm 0.3$ & $41.2 \pm 0.5$ \\
\hline \multirow[t]{3}{*}{ Krichauff } & $\mathrm{KCl}$ & & $39.0 \pm 0.5$ & $41.5 \pm 0.7$ & $40.6 \pm 0.9$ \\
\hline & $\mathrm{KNO}_{3}$ & $31.7 \pm 0.71$ & $34.0 \pm 1.0$ & $32.6 \pm 0.5$ & $37.5 \pm 1.4$ \\
\hline & $\mathrm{K}_{2} \mathrm{SO}_{4}$ & & $39.8 \pm 0.6$ & $40.0 \pm 0.3$ & $42.5 \pm 1.1$ \\
\hline
\end{tabular}

Analysis of variance

\begin{tabular}{ll}
\hline K-form $(F)$ & $P<.001$ \\
K-level $(L)$ & $P<.001$ \\
Cultivar $(C)$ & $P<.001$ \\
$F * L$ & $P<.001$ \\
$F * C$ & $P=.066$ \\
$L * C$ & NS \\
$F * L * C$ & NS
\end{tabular}

difference between the two cultivars in both shoot and root biomass.

\subsection{Potassium uptake}

Application of $\mathrm{K}$ fertilizers significantly increased $\mathrm{K}$ concentrations in shoots and roots of both cultivars $(P<.001) . \mathrm{K}$ concentrations in shoots and roots in both cultivars were also affected by the forms of $\mathrm{K}$ fertilizers significantly $(P<.001)$ (Tables 4 and 5$)$. K concentrations in the treatments of $\mathrm{KNO}_{3}$ were generally lower than those in the other treatments.

\subsection{Cadmium uptake}

$\mathrm{Cd}$ concentrations in plant roots were different from that of shoots. With the exception of the $\mathrm{KCl}$ treatment, the $\mathrm{Cd}$

Table 5

$\mathrm{K}$ concentrations in roots of spring wheat plants grown in pot culture with different forms and levels of K-fertilizers $\left(\mathrm{g} \mathrm{kg}^{-1}\right)$

\begin{tabular}{llrrrr}
\hline Cultivar & Form & \multicolumn{4}{c}{ Levels of potassium addition $\left(\mathrm{mg} \mathrm{kg}^{-1}\right)$} \\
\cline { 3 - 6 } & & \multicolumn{1}{c}{0} & \multicolumn{1}{c}{55} & \multicolumn{1}{l}{110} & \multicolumn{1}{l}{166} \\
\hline Brookton & $\mathrm{KCl}$ & & $10.1 \pm 0.4$ & $11.6 \pm 1.1$ & $13.1 \pm 0.7$ \\
& $\mathrm{KNO}_{3}$ & $8.3 \pm 0.4$ & $8.6 \pm 0.8$ & $10.6 \pm 0.7$ & $10.4 \pm 0.5$ \\
& $\mathrm{~K}_{2} \mathrm{SO}_{4}$ & & $12.8 \pm 0.3$ & $14.8 \pm 0.6$ & $14.1 \pm 0.6$ \\
Krichauff & $\mathrm{KCl}$ & & $10.1 \pm 0.2$ & $13.5 \pm 0.4$ & $11.7 \pm 0.4$ \\
& $\mathrm{KNO}_{3}$ & $7.6 \pm 0.5$ & $10.2 \pm 0.4$ & $9.1 \pm 0.5$ & $10.2 \pm 0.4$ \\
& $\mathrm{~K}_{2} \mathrm{SO}_{4}$ & & $13.5 \pm 0.5$ & $13.5 \pm 0.4$ & $14.1 \pm 0.9$
\end{tabular}

Analysis of variance

$\begin{array}{ll}\text { K-form }(F) & P<.001 \\ \text { K-level }(L) & P<.001 \\ \text { Cultivar }(C) & \mathrm{NS} \\ F * L & P<.001 \\ F * C & \mathrm{NS} \\ L * C & \mathrm{NS} \\ F * L * C & P=.031\end{array}$


Table 6

$\mathrm{Cd}$ concentrations in roots of spring wheat plants grown in pot culture with different forms and levels of K-fertilizers $\left(\mathrm{mg} \mathrm{kg}^{-1}\right)$

\begin{tabular}{rlllll}
\hline Cultivar & Form & \multicolumn{4}{l}{ Levels of potassium addition $\left(\mathrm{mg} \mathrm{kg}^{-1}\right)$} \\
\cline { 3 - 6 } & & 0 & 55 & 110 & 166 \\
\hline Brookton & $\mathrm{KCl}$ & $194.6 \pm 10.0$ & $220.2 \pm 8.0$ & $275.6 \pm 36.1$ \\
$\mathrm{KNO}_{3}$ & $180.7 \pm 18.7$ & $194.2 \pm 30.7$ & $183.1 \pm 15.2$ & $185.2 \pm 10.4$ \\
$\mathrm{~K}_{2} \mathrm{SO}_{4}$ & & $143.2 \pm 9.6$ & $142.5 \pm 5.1$ & $141.4 \pm 6.3$ \\
Krichauff & $\mathrm{KCl}$ & & $158.9 \pm 14.9$ & $207.3 \pm 17.1$ & $138.4 \pm 5.5$ \\
$\mathrm{KNO}_{3}$ & $152.6 \pm 5.1$ & $159.8 \pm 13.0$ & $160.0 \pm 5.2$ & $159.3 \pm 7.2$ \\
$\mathrm{~K}_{2} \mathrm{SO}_{4}$ & & $122.3 \pm 5.6$ & $145.2 \pm 8.2$ & $135.5 \pm 9.6$
\end{tabular}

Analysis of variance

K-form $P<.001$

(F)

K-level NS

$(L)$

Cultivar $P<.001$

$(C)$

$F * L \quad P=.010$

$F * C \quad P=.022$

$L * C \quad P=.066$

$F * L * C \quad P=.015$

concentrations in the roots of both Brookton and Krichauff were decreased marginally in the treatments of $\mathrm{K}_{2} \mathrm{SO}_{4}$ or unaffected in the treatments of $\mathrm{KNO}_{3}$ with increasing application $\mathrm{K}$ fertilizers (Table 6 ). Interaction effects between forms and amounts of $\mathrm{K}$ fertilizers on $\mathrm{Cd}$ concentrations in plant shoots and roots were also significant $(P<.001)$.

$\mathrm{Cd}$ accumulation in plant shoots of both Brookton and Krichauff increased gradually with increasing application of $\mathrm{K}$ fertilizers in the treatments of $\mathrm{KCl}$ and $\mathrm{K}_{2} \mathrm{SO}_{4}$ (Table 7). The concentrations of $\mathrm{Cd}$ in shoots increased from $37.5 \mathrm{mg}$ $\mathrm{kg}^{-1}$ dry weight (for Brookton) to $81.4 \mathrm{mg} \mathrm{kg}^{-1}$ dry weight, and $42.9 \mathrm{mg} \mathrm{kg}^{-1}$ dry weight (for Krichauff) to $86.8 \mathrm{mg} \mathrm{kg}^{-1}$ dry weight, which were about doubled (Table

Table 7

$\mathrm{Cd}$ concentrations in shoots of spring wheat plants grown in pot culture with different forms and levels of $\mathrm{K}$-fertilizers $\left(\mathrm{mg} \mathrm{kg}^{-1}\right)$

\begin{tabular}{llllll}
\hline Cultivar & Form & \multicolumn{4}{c}{ Levels of potassium addition $\left(\mathrm{mg} \mathrm{kg}^{-1}\right)$} \\
\cline { 3 - 6 } & & 0 & 55 & 110 & 166 \\
\hline Brookton & $\mathrm{KCl}$ & & $68.6 \pm 2.7$ & $66.3 \pm 2.8$ & $71.3 \pm 2.5$ \\
& $\mathrm{KNO}_{3}$ & $37.5 \pm 3.5$ & $37.4 \pm 3.5$ & $42.7 \pm 3.1$ & $57.0 \pm 5.5$ \\
& $\mathrm{~K}_{2} \mathrm{SO}_{4}$ & & $71.1 \pm 4.5$ & $71.1 \pm 2.4$ & $81.4 \pm 4.0$ \\
Krichauff & $\mathrm{KCl}$ & & $69.4 \pm 2.4$ & $70.3 \pm 1.1$ & $74.6 \pm 1.7$ \\
& $\mathrm{KNO}_{3}$ & $42.9 \pm 2.2$ & $45.1 \pm 4.4$ & $43.0 \pm 3.0$ & $64.1 \pm 2.1$ \\
& $\mathrm{~K}_{2} \mathrm{SO}_{4}$ & & $75.7 \pm 2.1$ & $79.2 \pm 1.9$ & $86.8 \pm 2.5$
\end{tabular}

Analysis of variance

\begin{tabular}{ll}
\hline K-form $(F)$ & $P<.001$ \\
K-level $(L)$ & $P<.001$ \\
Cultivar $(C)$ & $P<.001$ \\
$F * L$ & $P<.001$ \\
$F * C$ & $\mathrm{NS}$ \\
$L * C$ & $\mathrm{NS}$ \\
$F * L * C$ & $\mathrm{NS}$
\end{tabular}

K-level $(L) \quad P<.001$

Cultivar $(C) \quad P<.001$

$F * L \quad P<.001$

$L * C \quad$ NS

$F * L * C \quad \mathrm{NS}$
Table 8

Total Cd uptake by spring wheat plants grown in pot culture with different forms and levels of K-fertilizers $\left(\mu \operatorname{g~pot}^{-1}\right)$

\begin{tabular}{|c|c|c|c|c|c|}
\hline \multirow[t]{2}{*}{ Cultivar } & \multirow[t]{2}{*}{ Form } & \multicolumn{4}{|c|}{ Levels of potassium addition $\left(\mathrm{mg} \mathrm{kg}^{-1}\right)$} \\
\hline & & 0 & 55 & 110 & 166 \\
\hline \multirow[t]{3}{*}{ Brookton } & $\mathrm{KCl}$ & & $260.8 \pm 7.6$ & $238.0 \pm 9.9$ & $244.2 \pm 22.4$ \\
\hline & $\mathrm{KNO}_{3}$ & $176.7 \pm 4.4$ & $203.0 \pm 12.2$ & $208.8 \pm 12.1$ & $213.8 \pm 12.2$ \\
\hline & $\mathrm{K}_{2} \mathrm{SO}_{4}$ & & $192.4 \pm 10.9$ & $210.5 \pm 14.7$ & $229.8 \pm 3.6$ \\
\hline \multirow[t]{3}{*}{ Krichauff } & $\mathrm{KCl}$ & & $138.2 \pm 1.3$ & $224.7 \pm 7.0$ & $194.4 \pm 10.7$ \\
\hline & $\mathrm{KNO}_{3}$ & $169.0 \pm 11.9$ & $221.9 \pm 13.2$ & $157.9 \pm 0.9$ & $218.0 \pm 14.9$ \\
\hline & $\mathrm{K}_{2} \mathrm{SO}_{4}$ & & $182.3 \pm 12.6$ & $234.7 \pm 9.7$ & $231.2 \pm 8.5$ \\
\hline
\end{tabular}

Analysis of variance

K-form $P<.001$

$(F)$

K-level $\quad P<.001$

$(L)$

Cultivar NS

(C)

$F * L \quad P<.001$

$F * C \quad \mathrm{NS}$

$L * C \quad$ NS

$F * L * C \quad \mathrm{NS}$

7). In the $\mathrm{KNO}_{3}$ treatment, however, the $\mathrm{Cd}$ concentrations were not significantly affected by increasing the application of $\mathrm{K}$ fertilizers except for the highest level (K3). The grand mean of $\mathrm{Cd}$ concentrations in the treatments of $\mathrm{KNO}_{3}$ was $46.2 \mathrm{mg} \mathrm{kg}^{-1}$ dry weight, which was much lower than the other treatments $\left(62.6\right.$ and $68.2 \mathrm{mg} \mathrm{kg}^{-1}$ dry weight from the treatments of $\mathrm{KCl}$ and $\mathrm{K}_{2} \mathrm{SO}_{4}$, respectively).

The two cultivars showed some differences in total $\mathrm{Cd}$ uptake. For Brookton, the total $\mathrm{Cd}$ uptake in the treatments of $\mathrm{K}_{2} \mathrm{SO}_{4}$ and $\mathrm{KNO}_{3}$ were very similar, and were lower than in the treatments of $\mathrm{KCl}$. For Krichauff, however, the total $\mathrm{Cd}$ uptake was quite different at lower $\mathrm{K}$ levels among the three treatments, but were close at the highest $\mathrm{K}$ levels (Table 8). The distribution of $\mathrm{Cd}$ in shoots and roots of the two cultivars was significantly different $(P<.001)$ between the two cultivars (data not shown), although the total $\mathrm{Cd}$ uptake was similar (grand mean: 73.0 and $73.3 \mathrm{mg} \mathrm{kg}^{-1}$ for Brookton and Krichauff, respectively). Generally, Cd concentrations were lower in shoots and higher in roots of Brookton than those in Krichauff (Tables 6 and 7).

\section{Discussion}

Soil contamination with $\mathrm{Cd}$ exists in many agricultural soils, and food ingestion is a major pathway of $\mathrm{Cd}$ entry to human body. Minimizing the concentrations of $\mathrm{Cd}$ in agricultural produce is therefore desirable for the reduction of the human risk of soil $\mathrm{Cd}$ contamination. The effect of $\mathrm{K}$ fertilizers on plant accumulation of cadmium has rarely been studied in detail in the past. However, it was pointed out by Grant et al. (1999) that the effect of K fertilizers may be due more to the accompanying anions of the salt. Results obtained 
in the present study showed that an increase in the application of $\mathrm{K}$ fertilizers increased $\mathrm{Cd}$ concentrations in both shoots and roots of two wheat cultivars irrespective of the forms of fertilizers (Tables 6 and 7), which suggests that $K$ itself may increase plant uptake of $\mathrm{Cd}$. This is particularly true in the case of $\mathrm{KNO}_{3}$ treatment, an increase in $\mathrm{K}$ addition as $\mathrm{KNO}_{3}$ significantly increased $\mathrm{Cd}$ concentrations in plant shoots (Table 8). However, the mechanisms of $\mathrm{K}-\mathrm{Cd}$ interactions in plant uptake of $\mathrm{Cd}$ need to be elucidated further.

The various potassium forms differed in terms of their effects on $\mathrm{Cd}$ accumulation in plants. Some evidence has been reported on $\mathrm{Cl}^{-}$and $\mathrm{SO}_{4}^{2-}$ increasing $\mathrm{Cd}$ uptake by plants (Bingham et al., 1986; Sparrow et al., 1994; McLaughlin et al., 1995). When the level of $\mathrm{K}$ addition increased from 0 to $55 \mathrm{mg} \mathrm{kg}^{-1}$ soil, the application of $\mathrm{KCl}$ and $\mathrm{K}_{2} \mathrm{SO}_{4}$ resulted in $60-90 \%$ increase in Cd concentration in shoots, while the application of $\mathrm{KNO}_{3}$ only resulted in marginal increase in $\mathrm{Cd}$ concentration in shoots. Chloride is well known for forming relatively stable complexes with $\mathrm{Cd}, \mathrm{CdCl}^{+}$and $\mathrm{CdCl}_{2}^{0}$. Simple stability calculations indicate that the formation of $\mathrm{Cd}$ complexes with $\mathrm{Cl}^{-}$become significant when $\mathrm{Cl}^{-}$concentration in soil solution rise above about $10 \mathrm{mM}$ (Lindsay, 1979; Norvell et al., 2000), which tends to shift $\mathrm{Cd}$ from solid to soil solution, thus enhancing $\mathrm{Cd}$ solubility and bioavailability. $\mathrm{As}^{-} \mathrm{Cl}^{-}$is a major anion contributing to soil salinity, several studies have now demonstrated that $\mathrm{Cd}$ concentrations in wheat grains are positively related to soil salinity (Norvell et al., 2000; $\mathrm{Wu}$ et al., 2002). It was also suggested that complexes $\mathrm{CdCl}_{n}^{2-n}$ and $\mathrm{CdSO}_{4}^{0}$ were available to plants equivalent to $\mathrm{Cd}^{2+}$ (Smolders and McLaughlin, 1996; Smolders et al., 1996; McLaughlin et al, 1998a,b). Sulphate complexes with $\mathrm{Cd}$ are not so stable as chloride complexes with $\mathrm{Cd}$ (Lindsay, 1979), and the results of both nutrient solution and soil experiments of McLaughlin et al. (1998a,b) showed no significant increasing effects of $\mathrm{SO}_{4}^{2-}$ on $\mathrm{Cd}$ uptake by plants although $\mathrm{CdSO}_{4}^{0}$ was equivalent to $\mathrm{Cd}^{2+}$. They suggested that $\mathrm{SO}_{4}^{2-}$ would not have the same effect on plant uptake of $\mathrm{Cd}_{\text {as }} \mathrm{Cl}^{-}$. Li et al. (1994) reported that $\mathrm{Cl}^{-}$ was much more closely related to $\mathrm{Cd}$ accumulation as $\mathrm{SO}_{4}^{2-}$ in sunflower kernels. Our data, however, indicated that the addition of $\mathrm{K}_{2} \mathrm{SO}_{4}$ and $\mathrm{KCl}$ significantly increased $\mathrm{Cd}$ concentrations in plants of both cultivars, and that there was no statistically significant difference between $\mathrm{KCl}$ and $\mathrm{K}_{2} \mathrm{SO}_{4}$. Interestingly, although the shoot $\mathrm{Cd}$ concentrations were positively associated with the addition of $\mathrm{KCl}$ and $\mathrm{K}_{2} \mathrm{SO}_{4}$, the root $\mathrm{Cd}$ concentrations were not. Instead, the latter were unaffected or marginally decreased by the addition of $\mathrm{K}_{2} \mathrm{SO}_{4}$. In general, the changes in root $\mathrm{Cd}$ concentrations were less drastic than in shoot $\mathrm{Cd}$ concentrations, which may imply that $\mathrm{Cl}^{-}$and $\mathrm{SO}_{4}^{2-}$ may affect the root-to-shoot translocation of $\mathrm{Cd}$ as well.

Despite the increasing evidence showing the effect of $\mathrm{Cl}^{-}$and $\mathrm{SO}_{4}^{2-}$ on plant uptake of $\mathrm{Cd}$, there is no evidence to show the uptake of intact $\mathrm{Cd}$ complexes with $\mathrm{Cl}^{-}$and $\mathrm{SO}_{4}^{2-}$ by plant roots either in solution and pot cultures. Further studies are needed to examine the effects of K-fertilizers on $\mathrm{Cd}$ uptake and to investigate the mechanisms involved in the interactions between $\mathrm{Cd}_{\text {and }} \mathrm{Cl}^{-}$and $\mathrm{SO}_{4}^{2-}$ in soilplant systems, which may reveal useful information to guide proper agricultural practices to ensure low $\mathrm{Cd}$ accumulation in agricultural produce.

\section{Acknowledgements}

This project was supported by the Natural Science Foundation of China (4225002), and the "Recruiting Outstanding Overseas Chinese Scientists" scheme of the Chinese Academy of Sciences, China. We thank Prof K.X. Tian for providing instruction and help during the pot culture, and Dr. D.Y. Chen, Agilent Technologies for ICPMS analysis.

\section{References}

Basta NT, Raun WR, Gavi F. Wheat grain cadmium under long-term fertilization and continuous winter wheat production. Better Crops 1998; 82(19):14-5.

Bingham FT, Garrison S, Strong JE. The effect of chloride on the availability of cadmium. J Environ Qual 1984;13:71-4.

Bingham FT, Garrison S, Strong JE. The effect of sulfate on the availability of cadmium. Soil Sci 1986;141:172-7.

Cai S, Yue L, Hu Z, Zhong X, Ye Z, Xu H, et al. Cadmium exposure and health effects among residents in an irrigation area with ore dressing wastewater. Sci Total Environ 1990;90:67-73.

Chaney RL, Hornick SB. Accumulation and effects of cadmium on crops Cadmium 77. Proc 1st Int Cadmium Conf, San Francisco. London: Metal Bulletin; 1978. p. 125-40.

Eriksson JE. Effects of nitrogen-containing fertilizers on solubility and plant uptake of cadmium. Water Air Soil Pollut 1990;49:355-68.

Grant CA, Baily LD. Nitrogen, phosphorus and zinc management effects on grain yield and cadmium concentration in two cultivars of durum wheat. Can J Plant Sci 1997;78:63-70.

Grant CA, Baily LD, Therrien MC. Effect of N, P, and $\mathrm{KCl}$ fertilizers on grain yield and Cd concentration of malting barley. Fertil Res 1996;45: $153-61$.

Grant CA, Baily LD, McLaughlin MJ, et al. Management factors which influence cadmium concentrations in crops. In: McLaughlin MJ, Singh BR, editors. Cadmium in soils and plants. Dordrecht, The Netherlands: Kluwer Academic Publishing; 1999. p. 151-98.

Li YM, Chaney RL, Schneiter AA. Effect of soil chloride level on cadmium concentration in sunflower kernels. Plant Soil 1994;167:275-80.

Lindsay WL. Chemical equilibria in soils. New York: Wiley; 1979.

Lu RK. Analytical methods for soils and agricultural chemistry. Beijing: China Agricultural Science and Technology Press; 1999.

Mair NA, McLaughlin MJ, Heap M, Butt M, Smart MK. Effects of nitrogen source and calcium lime on soil $\mathrm{pH}$ and potato yield, leaf chemical composition, and tuber cadmium concentrations. J Plant Nutr 2002; 25(3):523-44.

McLaughlin MJ, Palmer LT, Tiller KG, Beech TA, Smart MK. Increased soil salinity causes elevated cadmium concentrations in field-grown potato tubers. J Environ Qual 1994;23:1013-8.

McLaughlin MJ, Mair NA, Freeman K, Tiller KG, Williams CMJ, Smart MK. Effect of potassic and phosphatic fertilizer type, fertilizer Cd concentration and zinc rate on cadmium uptake by potatoes. Fertil Res $1995 ; 40: 63-70$. 
McLaughlin MJ, Andrew SJ, Smart MK, Smolders E. Effects of sulfate on cadmium uptake by Swiss chard: I. Effects of complexation and calcium competition in nutrient solutions. Plant Soil 1998;202:211-6.

McLaughlin MJ, Lambrechts RM, Smolders E, Smart MK. Effects of sulfate on cadmium uptake by Swiss chard: II. Effects due to sulfate addition to soil. Plant Soil 1998;202:217-22.

Nordberg GF, Jin T, Kong Q, Ye T, Cai S, Wang Z, et al. Biological monitoring of cadmium exposure and renal effects in a populated group residing in a polluted area in China. Sci Total Environ 1997;199:111-4.

Norvell WA, Wu J, Hopkins DG, Welch RM. Association of cadmium in durum wheat grain with soil chloride and chelate-extractable soil cadmium. Soil Sci Soc Am J 2000;64:2162-8.

Oliver DP, Schultz JE, Tiller KG, Merry RH. The effect of crop rotations and tillage practices on cadmium concentration in wheat grain. Aust J Agric Res 1993;44:1221-34.

Smolders E, McLaughlin MJ. Effect of $\mathrm{Cl}$ on Cd uptake by Swiss chard in nutrient solutions. Plant Soil 1996;179:57-64.

Smolders E, McLaughlin MJ, Tiller KG. Influence of chloride on $\mathrm{Cd}$ availability to Swiss chard: a resin buffered solution culture system. Soil Sci Soc Am J 1996;60:1443-7.

Sparrow LA, Saladini AA, Jonstone J. Field studies of $\mathrm{Cd}$ in potatoes
(Solanum tuberosum L.): III. Response of cv. Russet Burbank to sources of banded potassium. Aust J Agric Res 1994;45:243-9.

Willaert G, Verloo M. Effects of various nitrogen fertilizers on the chemical and biological activity of major and trace elements in a cadmium contaminated soil. Pedologie 1992;43:83-91.

Wu J, Norvell WA, Hopkins DG, Welch RM. Spatial variability of grain cadmium and soil characteristics in a durum wheat field. Soil Sci Soc Am J 2002;66:268-75.

Zhu YG. Effects of external potassium (K) supply on the uptake of ${ }^{137} \mathrm{Cs}$ by spring wheat (Triticum aestivum, cv. Tonic): a large-scale hydroponic study. J Environ Radioact 2001;55:303-14.

Zhu YG, Shaw G, Nisbet AF, Wilkins BT. Effects of external potassium supply on compartmentation and flux characteristics of radiocaesium in intact spring wheat roots. Ann Bot 1999;84:639-44.

Zhu YG, Shaw G, Nisbet AF, Wilkins BT. Effect of potassium supply on the uptake of ${ }^{137} \mathrm{Cs}$ by spring wheat (Triticum aestivum, cv. Tonic): a lysimeter study. Radiat Environ Biophys 2000;39:283-90.

Zhu YG, Shaw G, Nisbet AF, Wilkins BT. Effect of potassium supply and plant age on the uptake of radiocaesium $\left({ }^{137} \mathrm{Cs}\right)$ by broad bean (Vicia faba): interpretation of results from a large-scale hydroponic study. Environ Exp Bot 2002;47:173-87. 